\title{
Endoscopic analysis of colorectal serrated lesions with cancer
}

\author{
SHUICHIRO NAGATA ${ }^{1}$, KEIICHI MITSUYAMA ${ }^{1}$, HIROSHI KAWANO ${ }^{2}$, TETSUHIRO NODA ${ }^{1}$, \\ YASUHIKO MAEYAMA ${ }^{1}$, MICHITA MUKASA ${ }^{1}$, HIDETOSHI TAKEDATSU ${ }^{1}$, SHINICHIRO YOSHIOKA ${ }^{1}$, \\ KOTARO KUWAKI $^{1}$, JUN AKIBA ${ }^{3}$, OSAMU TSURUTA ${ }^{1}$ and TAKUJI TORIMURA ${ }^{1}$ \\ ${ }^{1}$ Division of Gastroenterology, Department of Medicine, Kurume University School of Medicine, Kurume, \\ Fukuoka 830-0011; ${ }^{2}$ Department of Gastroenterology, St. Mary's Hospital, Kurume, Fukuoka 830-8543; \\ ${ }^{3}$ Department of Pathology, Kurume University School of Medicine, Kurume, Fukuoka 830-0011, Japan
}

Received February 11, 2016; Accepted July 7, 2017

DOI: $10.3892 / \mathrm{ol} .2018 .8386$

\begin{abstract}
Serrated lesions, including hyperplastic polyps (HPs), traditional serrated adenomas (TSAs) and sessile serrated adenomas/polyps (SSA/Ps), are important contributors to colorectal carcinogenesis. The aim of the present study was to analyze the potential of conventional endoscopy and advanced endoscopic imaging techniques to delineate the characteristic features of serrated lesions with cancer. The present study was a retrospective analysis of the data of 168 patients who had undergone colonoscopy, and a total of 228 serrated lesions (77 HPs, 58 TSAs, 84 SSA/Ps, 9 SSA/P plus TSAs) have been identified in these patients. A cancer component was identified in $2.6 \%$ of HPs, $13.8 \%$ of TSAs and $10.7 \%$ of SSA/Ps, but none of SSA/P plus TSAs. Compared with the lesions without cancer, the lesions with cancer exhibited a larger size (HP, TSA and SSA/P), a reddish appearance (SSA/P), a two-tier raised appearance (HP and SSA/P), a central depression (HP, TSA and SSA/P), the type $\mathrm{V}$ pit pattern (HP, TSA and SSA/P), and/or the type III capillary pattern (TSA and SSA/P). Deep invasion was identified in $50.0 \%$ of HPs, $12.5 \%$ of TSAs and $55.6 \%$ of SSA/Ps with cancer. The Ki-67 proliferative zone was distributed diffusely within the area of the cancer, but partially within the non-cancer area of HPs, TSAs and SSA/Ps. The lesion types were also analyzed on the basis of mucin phenotype. The present study suggested that a detailed endoscopic analysis of serrated lesions with cancer is useful for delineating characteristic features, and the analysis aids treatment selection.
\end{abstract}

\section{Introduction}

The majority of colorectal cancer cases are considered to arise from conventional adenomas, on the basis of the

Correspondence to: Dr Keiichi Mitsuyama, Division of Gastroenterology, Department of Medicine, Kurume University School of Medicine, 67 Asahi-machi, Kurume, Fukuoka 830-0011, Japan E-mail: ibd@med.kurume-u.ac.jp

Key words: serrated lesions, colorectal cancer, capillary pattern, pit pattern concept of the adenoma-carcinoma sequence $(1,2)$. By contrast, serrated lesions, including hyperplastic polyps (HPs), traditional serrated adenomas (TSAs), and sessile serrated polyp/adenomas (SSA/Ps) (3-6), may be morphologically and genetically distinct. Additionally, HPs, TSAs and SSA/Ps may be linked to microsatellite unstable colorectal cancer. Therefore, the concept of a HP-serrated adenoma-carcinoma pathway has been suggested (7-9).

Colonoscopy is the only technique available for the reliable detection and removal of colorectal lesions. A number of advanced endoscopic imaging techniques, including chromoendoscopy (CE) and narrow-band imaging (NBI), which enhance the detection and discrimination of mucosal lesions, have been developed to improve the accuracy of conventional endoscopy $(10,11)$. Using CE and NBI, the present authors and others have extensively investigated the endoscopic characteristics of colorectal serrated lesions, particularly lesions without a coexisting cancer component (12-14).

There is growing evidence to show that serrated lesions, particularly TSAs and SSA/Ps, demonstrated a significant risk of developing colorectal cancer (15). Therefore, reliable discrimination of serrated lesions with cancer from those without cancer has important clinical implications and may condition therapeutic attitudes. It has been hypothesized that serrated lesions with cancer may be distinguishable using colonoscopy, particularly with one of the advanced endoscopic imaging techniques. However, limited data are available on the endoscopic features of serrated lesions with and without cancer $(16,17)$.

In the present study, it was hypothesized that a detailed endoscopic analysis of serrated lesions with cancer may permit delineation of their characteristic endoscopic features. These observations may be used by endoscopists to improve the endoscopic recognition of serrated lesions with cancer and assist treatment selection.

\section{Materials and methods}

Patient selection and study design. The present study was a retrospective analysis of the data of 168 patients (109 males, 59 females; mean age, 63.8 years; range, 28-87 years) who had undergone total colonoscopy at Kurume University Hospital (Kurume, Japan) between March 1999 and September 2013. 
Lesions were excluded if postoperative histopathological evaluation was impossible due to thermal or mechanical tissue damage caused by endoscopic resection procedures and if patients had other diseases at the same time. A total of 228 histologicalally confirmed serrated lesions were identified in the patients. Of these 228 serrated lesions, there were 77 HPs, 58 TSAs, 84 SSA/Ps and 9 SSA/P plus TSAs. The ethics committee of Kurume University Hospital approved the study protocol.

Endoscopic procedure. Bowel preparation for colonoscopy consisted of ingesting polyethylene glycol-electrolyte solution (volume, 2 1) on the morning of the procedure by all patients.

Colonoscopy was performed using white-light imaging by experienced colonoscopists. When colorectal lesions were detected, the leisions were examined by switching to the NBI mode by the press of a button in the control head of the endoscope. Subsequently, the lesions were observed by CE using indigo carmine and the white-light imaging mode. Finally, magnifying endoscopy with NBI and CE using crystal violet was performed.

Conventional endoscopic analysis. The lesions were classified on the basis of the size, shape, site and other characteristic features, including presence/absence of a reddish appearance, a central depression, a two-tier raised appearance and a mucus cap $(12,13)$. These characteristics were determined once the images were reviewed by two of the study investigators.

Pit pattern analysis. Using magnifying CE, the pit patterns were classified into one of five types (I to V) according to classification criteria described by of Kudo et al $(18,19)$ and Tobaru et al $(20)$. Type I is represented by regular round crypts, type II is represented by stellar or papillary crypts, type III is represented by small tubular or roundish crypts $\left(\mathrm{III}_{\mathrm{S}}\right)$ or large tubular or roundish crypts $\left(\mathrm{III}_{\mathrm{L}}\right)$, type IV is represented by branch- or gyrus-like crypts, and type $\mathrm{V}$ is represented by irregular or non-structural crypts. The majority of type I and II lesions are non-neoplastic, whereas type III, IV and V lesions are typically neoplastic.

Capillary pattern analysis. Using NBI, the lesions were classified using Sano's capillary pattern classification $(21,22)$, with type I (faintly visible microvessels surrounding the pits) representing non-neoplastic lesions, type II (elongated vessels of increased thickness surrounding the pits) representing adenomas, and type III (type IIIa, unevenly sized vessels of increased thickness with branching and curtailed irregularity and type IIIb with nearly avascular or loose vessels with fragmentation) indicative of cancer.

Histopathological analysis. All tissues were fixed in $10 \%$ neutral-buffered formalin for 2 days at room temperature and embedded in paraffin. The sections were cut into sections with a thickness of $4 \mu \mathrm{m}$ and stained using hematoxylin ( $1 \mathrm{~min}$ ) and eosin $(3 \mathrm{~min})$ at room temperature. The sections were assessed using a light microscope (BX41; Olympus Corporation, Tokyo, Japan) by two pathologists who were blinded to the aims of the study. In accordance with the World Health Organization classification (6), each serrated lesion was classified as HP, TSA or SSA/P. In regard to the evaluation of the adenocarcinomatous component of the lesions, the lesions were histologically rated as well-differentiated, moderately differentiated or poorly differentiated, and the vertical depth of invasion was also assessed as previously described (23). He present study defined a cancer lesion as category 4 of the Vienna classification of gastrointestinal epithelial neoplasia non-invasive high grade neoplasia (24).

Immunohistochemistry. Immunohistochemistry was performed in $4-\mu \mathrm{m}$ paraffin sections using a peroxidase procedure with a Bond Polymer Refine Detection kit (cat. no. DS9800; Leica Microsystems, Ltd., Milton Keynes, UK). Peroxide blocking was performed using 3-4\% hydrogen peroxide at room temperature for $5 \mathrm{~min}$. Hydrogen peroxide was included in a Bond Polymer Refine Detection kit (cat. no. DS9800; Leica Microsystems, Ltd.). A light microscope (BX41) was used for analysis (x40 magnification). To delineate the proliferative zone in the crypts, Ki-67 immunostaining was performed using monoclonal antibodies against marker of proliferation Ki-67 (1:100, Dako; Agilent Technologies, Inc., Santa Clara, CA, USA). Specific antibodies to the mucins were used to define the gastric and intestinal phenotypes, including antibodies against human gastric mucin (HGM; 1:100; cat. no. 45M1; Novocastra Laboratories, Ltd., Newcastle, UK) and MUC5AC (1:200; cat. no. CLH2; Novocastra Laboratories Ltd.) which detects the gastric foveolar type of mucin, MUC6 (1:100; cat. no. CLH5; Novocastra Laboratories Ltd.) which detects the pyloric gland type of mucin, and mucin (MUC)2 (Ccp58; Novocastra Laboratories Ltd.) which detects the mucin produced by goblet cells and their precursors. Additionally, the antibody against cluster of differentiation (CD)10 (1:100; cat. no. 56C6; Novocastra Laboratories Ltd.) was used to detect mucin produced by the striated border on the luminal surface of the small intestinal absorptive cells. Rabbit anti-mouse immunoglobulin $\mathrm{G}$ was used as a secondary antibody (undiluted), and incubated at room temperature for $8 \mathrm{~min}$. The secondary antibody was included in a Bond Polymer Refine Detection kit (cat. no. DS9800; Leica Microsystems, Ltd.). Lesions were categorized as being of the gastric type if they were positive for HGM, MUC5AC or MUC6, as the small-intestinal type if they were positive for MUC2 and CD10, as the large-intestinal type if they were positive for MUC2 and negative for CD10, and as the mixed type when gastric and intestinal markers were positive (25-27).

Statistical analysis. The results were analyzed using SPSS version 12.0 (SPSS, Inc., Chicago, IL, USA. Student's t-test was used for the analysis of age and size, and the $\chi^{2}$ test for the analysis of sex, shape, site, type $\mathrm{V}$ pit pattern, type III capillary pattern, reddish appearance, two-tier raised appearance, central depression and adherent mucus cap. $\mathrm{P}<0.05$ was considered to indicate a statistically significant difference.

\section{Results}

Clinicopathological characteristics. The clinicopathological characteristics of the serrated lesions with and without cancer are presented in Table I. Of the 228 serrated lesions, $2.6 \%(2 / 77)$ HPs, $13.8 \%$ (8/58) TSAs, $10.7 \%$ (9/84) SSA/Ps and 0\% (0/9) of the SSA/P plus TSAs contained a carcinomatous component. The HPs, TSAs and SSA/Ps with cancer were significantly increased in size, compared with the HPs, TSAs and SSA/Ps without cancer: HPs (mean size), 19.0 vs. $7.4 \mathrm{~mm}, \mathrm{P}=0.0002$; TSAs, 17.2 vs. $11.1 \mathrm{~mm}, \mathrm{P}=0.0079$; SSA/P plus TSAs, 19.1 vs. 
Table I. Clinicopathological features of serrated lesions with and without cancer.

\begin{tabular}{|c|c|c|c|c|c|c|c|c|}
\hline \multirow[b]{2}{*}{ Parameters } & \multicolumn{2}{|c|}{$\mathrm{HP}$} & \multicolumn{2}{|c|}{$\mathrm{TSA}$} & \multicolumn{2}{|c|}{$\mathrm{SSA} / \mathrm{P}$} & \multicolumn{2}{|c|}{$\mathrm{SSA} / \mathrm{p}$ plus TSA } \\
\hline & $\begin{array}{c}\text { With } \\
\text { cancer }\end{array}$ & $\begin{array}{l}\text { Without } \\
\text { cancer }\end{array}$ & $\begin{array}{c}\text { With } \\
\text { cancer }\end{array}$ & $\begin{array}{l}\text { Without } \\
\text { cancer }\end{array}$ & $\begin{array}{c}\text { With } \\
\text { cancer }\end{array}$ & $\begin{array}{l}\text { Without } \\
\text { cancer }\end{array}$ & $\begin{array}{c}\text { With } \\
\text { cancer }\end{array}$ & $\begin{array}{c}\text { Without } \\
\text { cancer }\end{array}$ \\
\hline Age, years ${ }^{\mathrm{a}}$ & 61.5 & 62.1 & 67.4 & 65.2 & 74 & 64.3 & - & 55.1 \\
\hline \multicolumn{9}{|l|}{ Sex, n } \\
\hline Male & 2 & 62 & 7 & 29 & 4 & 51 & 0 & 6 \\
\hline Female & 0 & 13 & 1 & 21 & 5 & 24 & 0 & 3 \\
\hline Lesions, $\mathrm{n}$ & 2 & 75 & 8 & 50 & 9 & 75 & 0 & 9 \\
\hline Size, mm & 19.0 & 7.5 & 17.8 & 11.1 & 19.1 & 13.3 & - & 15.0 \\
\hline \multicolumn{9}{|l|}{ Shape, n } \\
\hline Sessile & 2 & 68 & 3 & 27 & 9 & 73 & 0 & 5 \\
\hline Protruded & 0 & 7 & 5 & 23 & 0 & 2 & 0 & 4 \\
\hline \multicolumn{9}{|l|}{ Site, $\mathrm{n}$} \\
\hline Cecum & 1 & 11 & 0 & 1 & 3 & 19 & 0 & 1 \\
\hline Ascending colon & 0 & 10 & 1 & 7 & 2 & 28 & 0 & 1 \\
\hline Transverse colon & 0 & 17 & 2 & 0 & 4 & 17 & 0 & 1 \\
\hline Descending colon & 0 & 2 & 0 & 4 & 0 & 1 & 0 & 0 \\
\hline Sigmoid colon & 1 & 20 & 1 & 18 & 0 & 7 & 0 & 5 \\
\hline Rectum & 0 & 15 & 4 & 20 & 0 & 3 & 0 & 1 \\
\hline
\end{tabular}

${ }^{\text {a}}$ Data is represented as the average. Is and IIa lesions were regarded as sessile, while Ip and Isp lesions were regarded as protruding. HP, hyperplastic polyp; TSA, traditional serrated adenoma; SSA/P, sessile serrated adenoma/polyp.

Table II. Advanced endoscopic features of serrated lesions with and without cancer.

\begin{tabular}{|c|c|c|c|c|c|c|c|c|}
\hline \multirow[b]{2}{*}{ Features } & \multicolumn{2}{|c|}{ HP } & \multicolumn{2}{|c|}{ TSA } & \multicolumn{2}{|c|}{$\mathrm{SSA} / \mathrm{P}$} & \multicolumn{2}{|c|}{ SSA/P plus TSA } \\
\hline & $\begin{array}{l}\text { With } \\
\text { cancer }\end{array}$ & $\begin{array}{l}\text { Without } \\
\text { cancer }\end{array}$ & $\begin{array}{l}\text { With } \\
\text { cancer }\end{array}$ & $\begin{array}{l}\text { Without } \\
\text { cancer }\end{array}$ & $\begin{array}{l}\text { With } \\
\text { cancer }\end{array}$ & $\begin{array}{l}\text { Without } \\
\text { cancer }\end{array}$ & $\begin{array}{l}\text { With } \\
\text { cancer }\end{array}$ & $\begin{array}{l}\text { Without } \\
\text { cancer }\end{array}$ \\
\hline \multicolumn{9}{|c|}{ Type $V$ pit pattern } \\
\hline Present & 1 & 0 & 1 & 0 & 4 & 0 & 0 & 0 \\
\hline Absent & 0 & 14 & 0 & 12 & 0 & 32 & 0 & 3 \\
\hline \multicolumn{9}{|c|}{ Type III capillary pattern } \\
\hline Absent & 0 & 0 & 1 & 0 & 5 & 0 & 0 & 0 \\
\hline Present & 1 & 21 & 0 & 13 & 0 & 35 & 0 & 1 \\
\hline
\end{tabular}

HP, hyperplastic polyp; TSA, traditional serrated adenoma; SSA/P, sessile serrated adenoma/polyp.

$13.7 \mathrm{~mm}, \mathrm{P}=0.0124$. The shape and site of the lesions did not differ significantly between the HPs, TSAs and SSA/Ps with and without cancer. Furthermore, the HPs, TSAs and SSA/Ps with and without cancer also showed no significant differences in the size or shape. Notably, SSA/Ps with cancer, but not HPs or TSAs with cancer, were preferentially located in the right colon.

Conventional endoscopic features. A comparison of the conventional endoscopic features between serrated lesions with and without cancer is shown in Fig. 1. A reddish appearance of the lesion was more frequently observed in SSA/Ps with cancer, compared with lesions without cancer (88.9 vs. 46.7\%; $\mathrm{P}=0.0166)$. A two-tier raised appearance was identified preferentially in HPs and SSA/Ps with cancer, compared with lesions without cancer (HP, 50.0 vs. $1.3 \%$; $\mathrm{P}<0.0001 ; \mathrm{SSA} / \mathrm{P}$, 66.7 vs. $9.3 \%, \mathrm{P}<0.0001)$. Furthermore, a central depression was observed more frequently in HPs, TSAs and SSA/Ps with cancer compared with lesions without (HP, 50.0 vs. $2.7 \%, \mathrm{P}=0.0006$; TSA, 25.0 vs. $0.0 \%, \mathrm{P}=0.0003$; SSA/Ps, 55.6 vs. $6.7 \%, \mathrm{P}<0.0001$ ). By contrast, an adherent mucus cap was not present at a higher frequency in HPs, TSAs or SSA/Ps with cancer compared with lesions without cancer. Examples of the endoscopic features of serrated lesions with cancer are presented in Fig. 2.

Advanced endoscopic features. The advanced endoscopic features of serrated lesions with and without cancer were subsequently compared (Table II; Fig. 3). In the CE images, information was available for 64 lesions. The type $\mathrm{V}$ pit 
A

Reddish appearance

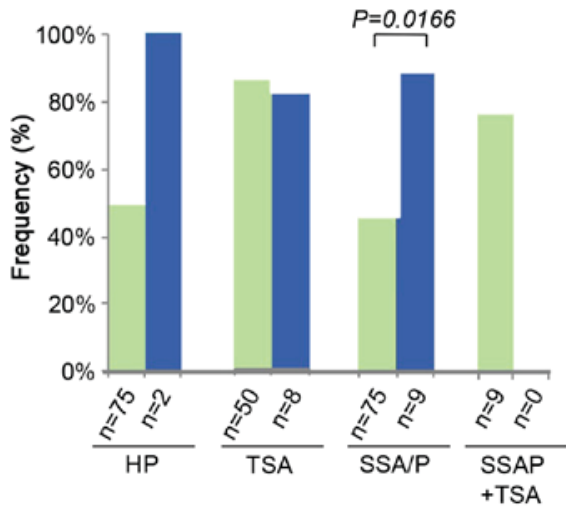

C

Central depression

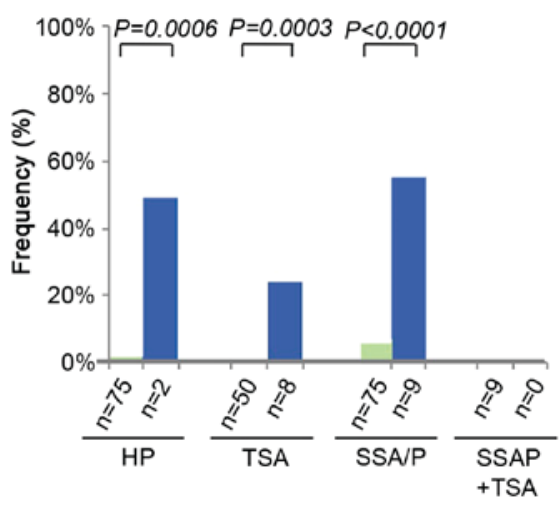

B Two-tier raised appearance

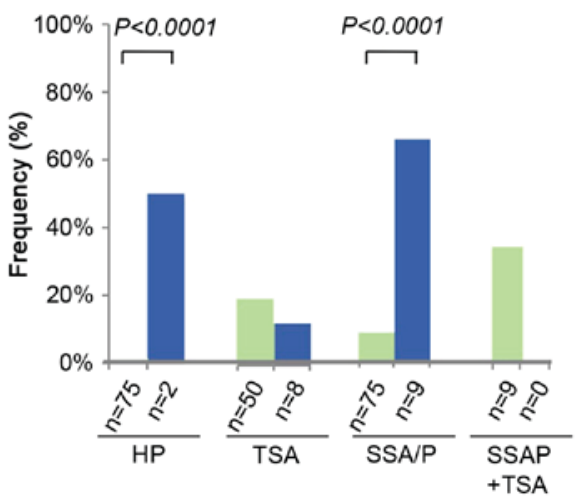

D

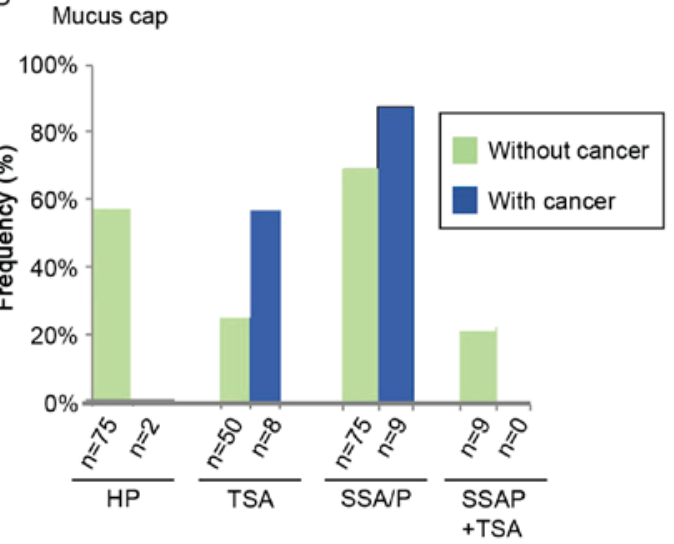

Figure 1. Endoscopic features of serrated lesions with and without cancer. (A) Reddish appearance; (B) two-tier raised appearance; (C) central depression; (D) mucus cap. HP, hyperplastic polyp; TSA, traditional serrated adenoma; SSA/P, sessile serrated adenoma/polyp.
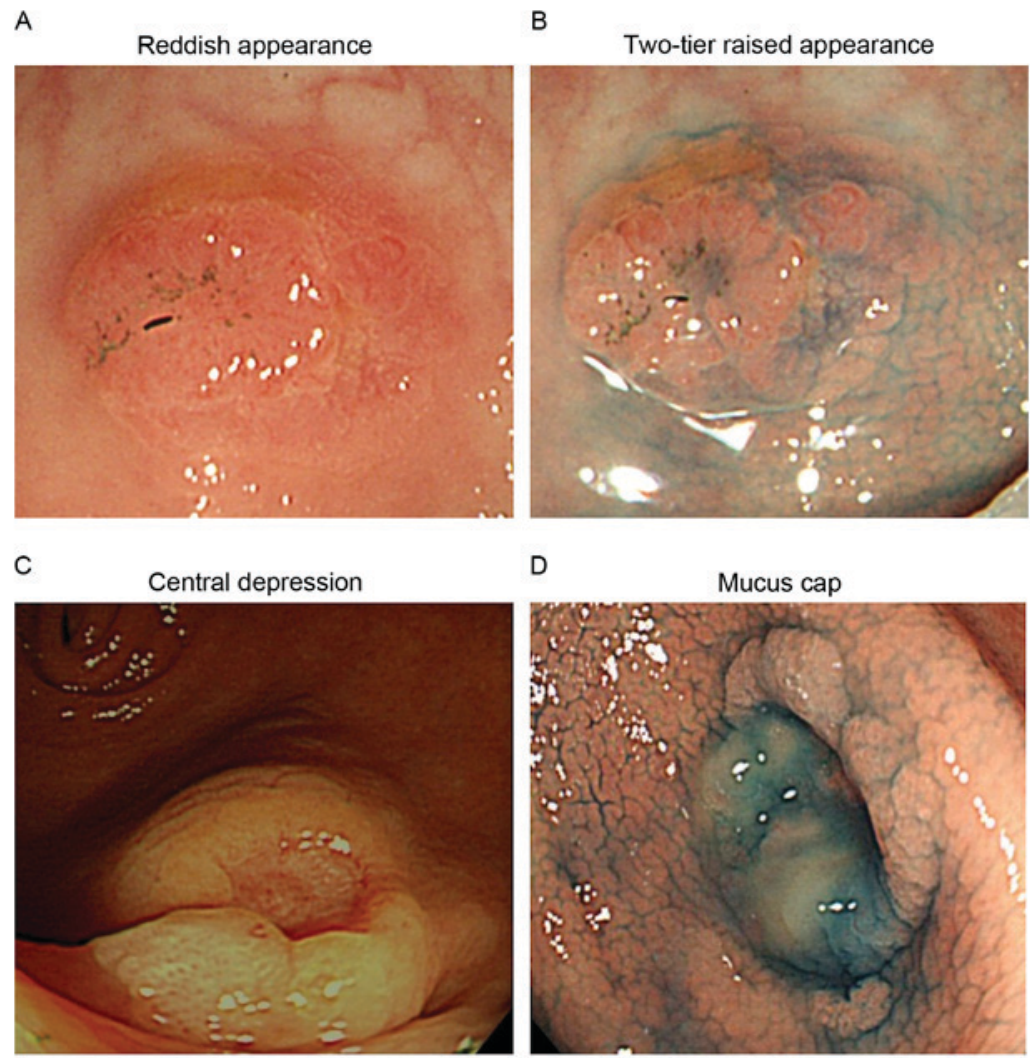

Figure 2. Endophotographs demonstrating the morphologic characteristics of serrated lesions. (A) Reddish appearance; (B) two-tier raised appearance; (C) central depression; (D) mucus cap. 
Table III. Histological appearance in the cancer areas and non-cancer areas of serrated lesions.

\begin{tabular}{|c|c|c|c|c|c|c|}
\hline \multirow[b]{2}{*}{ Features } & \multicolumn{2}{|c|}{$\mathrm{HP}(\mathrm{n}=2)$} & \multicolumn{2}{|c|}{$\operatorname{TSA}(\mathrm{n}=8)$} & \multicolumn{2}{|c|}{$\mathrm{SSA} / \mathrm{P}(\mathrm{n}=9)$} \\
\hline & $\begin{array}{c}\text { Cancer } \\
\text { area }\end{array}$ & $\begin{array}{c}\text { Non-cancer } \\
\text { area }\end{array}$ & $\begin{array}{c}\text { Cancer } \\
\text { area }\end{array}$ & $\begin{array}{c}\text { Non-cancer } \\
\text { area }\end{array}$ & $\begin{array}{c}\text { Cancer } \\
\text { area }\end{array}$ & $\begin{array}{c}\text { Non-cancer } \\
\text { area }\end{array}$ \\
\hline \multicolumn{7}{|l|}{ Depth of invasion } \\
\hline Intramucosal layer & 1 & - & 7 & - & 4 & - \\
\hline Submuscosal layer & 0 & - & 1 & - & 4 & - \\
\hline Muscularis propria or deeper & 1 & - & 0 & - & 1 & - \\
\hline \multicolumn{7}{|l|}{ Histological differentiation grade } \\
\hline Well-differentiated & 1 & - & 4 & - & 2 & - \\
\hline Moderately differentiated & 1 & - & 4 & - & 7 & - \\
\hline \multicolumn{7}{|l|}{ Ki-67-positive proliferation zone } \\
\hline Upper & 0 & 0 & 0 & 5 & 0 & 1 \\
\hline Lower & 0 & 2 & 0 & 1 & 0 & 8 \\
\hline Upper to lower & 2 & 0 & 8 & 2 & 9 & 0 \\
\hline \multicolumn{7}{|l|}{ Mucin phenotype } \\
\hline Large-intestinal & 0 & 0 & 3 & 1 & 0 & 0 \\
\hline Stomach & 1 & 0 & 0 & 0 & 0 & 0 \\
\hline Mixed & 1 & 2 & 5 & 7 & 9 & 9 \\
\hline
\end{tabular}

HP, hyperplastic polyp; TSA, traditional serrated adenoma; SSA/P, sessile serrated adenoma/polyp.

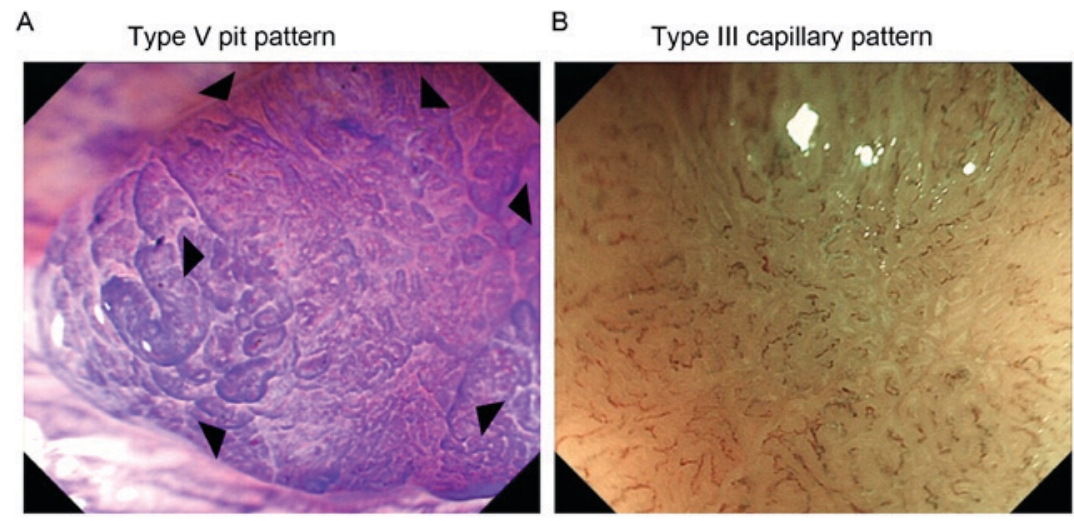

Figure 3. Advanced endophotographs illustrating the morphologic characteristics of serrated lesions. (A) The type V pit pattern on chromoendoscopy with crystal violet spraying, irregular crypts or non-structural crypts (indicated by black arrows). Original magnification, x20. (B) The type III capillary pattern on narrow-band imaging, unevenly sized vessels of increased thickness with branching and curtailed irregularity, or nearly avascular lesions or lesions containing loose vessels with fragmentation. Original magnification, $\mathrm{x} 40$.

pattern, represented by irregular crypts or non-structural crypts, was identified at an increased frequency in HPs, TSAs and SSA/Ps with cancer compared with lesions without cancer (HP, 100 vs. $0 \%, \mathrm{P}=0.00011$; TSA, 100 vs. $0 \%, \mathrm{P}=0.00031$; SSA/P, 100 vs. $0 \%, \mathrm{P}<0.0001)$.

As for the features on NBI, information was available for 76 lesions. The type III capillary pattern, represented by unevenly sized vessels of increased thickness with branching and curtailed irregularity, or nearly avascular lesions or lesions containing loose vessels with fragmentation, was observed more frequently in TSAs and SSA/Ps with cancer compared with lesions without cancer (TSA, 100 vs. $0 \%, \mathrm{P}=0.00018$; SSA/P, 100 vs. $0 \%, \mathrm{P}<0.0001)$.
Histological features. The histological features of serrated lesions with cancer are presented in Table III. As none of the 9 SSA/P plus TSA lesions exhibited any cancer component, SSA/P plus TSA lesions were excluded from the table. In regard to the cancer component, deep invasion (invasion of the muscularis propria or deeper) was identified in $50.0 \%(1 / 2)$ HPs with cancer, $12.5 \%$ (1/8) TSAs with cancer and $55.6 \%$ (5/9) SSA/Ps with cancer. The histological differentiation grade of the cancer was not significantly different among the HPs, TSAs and SSA/Ps.

The Ki-67-positive proliferative zone was distributed diffusely (from the upper to the lower parts of the crypts) within the cancer areas in all HPs $(2 / 2 ; 100 \%)$, TSAs $(8 / 8 ; 100 \%)$ and 
SSA/Ps (9/9; 100\%). By contrast, the proliferative zone within the non-cancer areas was partially distributed, as follows: HP (total, 2 cases), 2 cases in the lower part (2/2; 100\%); TSA (total, 8 cases), 5 cases in the upper part $(5 / 8 ; 62.5 \%), 1$ case in the lower part $(1 / 8 ; 12.5 \%)$ and 2 cases in the upper to the lower part $(2 / 8 ; 25.0 \%) ; \mathrm{SSA} / \mathrm{Ps}$ (total, 9 cases), 1 case in the upper part $(1 / 9 ; 11.1 \%)$ and 8 cases in the lower part $(8 / 9 ; 88.9 \%)$.

The lesion types in the cancer and non-cancer areas were classified on the basis of the mucin phenotype. There were 2 cases of HP, with cancer area classified as gastric phenotype in 1 case $(1 / 2 ; 50 \%)$ and mixed type (gastric plus intestinal type) in 1 case $(1 / 2 ; 50 \%)$. Non-cancer area in HP was classified as mixed phenotype in 2 cases $(2 / 2 ; 100 \%)$. There were 8 cases of TSA with cancer area classified as mixed phenotype in 5 cases $(5 / 8 ; 62.5 \%)$ and colonic phenotype in 3 cases $(3 / 8 ; 37.5 \%)$. Non-cancer area in TSA was classified as mixed phenotype in 7 cases $(7 / 8 ; 87.5 \%)$ and large intestinal phenotype in 1 case $(1 / 8 ; 12.5 \%)$. Additionally, there were 9 cases of $\mathrm{SSA} / \mathrm{P}$ with mixed phenotype for cancer and non-cancer areas in all cases $(9 / 9 ; 100 \%)$.

\section{Discussion}

There is accumulating evidence to show that colorectal serrated lesions are important precursors of colorectal cancer $(28,29)$. Previous studies by the present authors and others have demonstrated the potential of endoscopic imaging to discriminate between serrated lesions with and without cancer (12-14). However, limited data are available in regard to the characteristic endoscopic features of serrated lesions with and without cancer $(16,17)$. Therefore, the potential of conventional and advanced endoscopic imaging techniques was analyzed in the present study to delineate the characteristic features of colorectal serrated lesions with cancer.

In the present study, the cancer component was observed most frequently in TSAs (13.8\%), followed by SSA/Ps (10.7\%) and HPs (2.6\%). Previous studies have reported varying estimates of the frequency of cancer cases originating from each subtype of serrated lesions (15). This variability in frequency of cancer cases may reflect inconsistent diagnostic criteria used, inconsistent histological classification of the different subtypes of lesions, variations in the lesion detection rate among endoscopists, variable application of enhanced endoscopic modalities and different population selection criteria. However, the finding that the risk of malignant transformation was increased for TSAs and SSA/Ps compared with HPs in the present study is consistent with previous studies $(15,30)$. The malignant potential of each serrated lesion subtype remains unknown due to the lack of large-scale prospective studies.

The HPs, TSAs and SSA/Ps with cancer were increased in size compared with the same lesions without cancer, and it is hypothesized that there is an increased risk of malignant transformation in larger lesions of all subtypes. At present, it is not clear whether the threshold value of $10 \mathrm{~mm}$ to define advanced conventional adenomas is applicable to SSA/Ps (13-15).

A number of endoscopic characteristics have been identified as possible indicators for neoplastic lesions $(12,13)$. In the present study, a reddish appearance of SSA/Ps, a two-tier raised appearance of HPs and SSA/Ps, and a central depression in HPs, TSAs and SSA/Ps were observed more frequently in the presence of a cancer component in the lesions. The results of the present study were consistent with previously published studies $(13,17)$, and suggest that these characteristics are useful to discriminate between serrated lesions with and without cancer. However, the present study was unable to discriminate between serrated lesions with and without cancer on the basis of the presence of a 'mucus cap', in contradiction to previous studies $(13,17)$. A possible explanation for this discrepancy may be due to the methods used for estimating the endoscopic appearance as electronic video images were used in the present study whereas still images were used in the aforementioned studies $(13,17)$. Electronic video imaging enables dynamic observation of colorectal lesions, and hence, may provide additional details. A number of features may have been underestimated by still image assessment in previous studies.

In $\mathrm{CE}$, it is now well-established that the pit pattern is useful for diagnosing colorectal lesions (18-20). The type V pit pattern (irregular crypts or non-structural crypts) is a possible characteristic feature of colorectal cancer. Notably, in the present study, the type $\mathrm{V}$ pit pattern was only identified in HPs, TSAs and SSA/Ps with cancer, and not lesions without cancer, indicating that the type $\mathrm{V}$ pit pattern may be a specific indicator of cancer in all subtypes of serrated lesions.

NBI is an endoscopic technique that enables clear visualization of the microvasculature of colorectal lesions $(21,22)$. The type III capillary pattern (unevenly sized vessels of increased thickness with branching and curtailed irregularity or nearly avascular lesions or lesions containing loose vessels with fragmentation) represents a characteristic feature of colorectal cancer on NBI. In the present study, the type III capillary pattern was selectively identified in TSAs and SSA/Ps with cancer. This finding strongly suggests that the type III capillary pattern and the type $\mathrm{V}$ pit pattern are useful for discriminating lesions with a cancer component.

The results of the present study indicate the requirement for advanced endoscopic imaging techniques to discriminate between serrated lesions with and without cancer. However, the present study analyzed a limited number of cases by advanced imaging techniques: 64/228 and 76/228 lesions by $\mathrm{CE}$ and NBI, respectively. Additional studies including a larger number of lesions are required to evaluate the significance of the two novel imaging techniques.

Histological characteristics of the serrated lesions with cancer were also examined in the present study. The depth of cancer invasion is an important consideration in selecting the appropriate therapeutic strategy. In the present study, deeply invading cancer cases were observed more frequently in SSA/Ps compared with TSAs, which is in accordance with previous reports $(30,31)$. These results prompted the hypothesis that the transformation from SSA/P to invasive cancer may be rapid and occur even when the lesions are still small.

A conceptual way to define the subgroup of serrated lesions is on the basis of the location of the proliferation zones. In non-cancer areas, the Ki-67-positive proliferative zone was limited to a part of the crypts. Symmetric Ki-67 expression was typically observed in the lower crypts in HPs. TSAs exhibited 
symmetric expression in the upper crypts, and SSA/Ps exhibited asymmetric expression predominantly in the lower crypts. The results of the present study were consistent with previous reports (32). In the cancer areas, the positive proliferative zone was primarily distributed throughout the crypts in the HPs, TSAs and SSA/Ps, which is a characteristic feature of cancer lesions.

The mucin phenotype has been identified to be associated with the development and progression of gastrointestinal cancer (33). A previous study suggested that colorectal serrated lesions exhibit variable degrees of gastric and intestinal differentiation (26). In the present study, it was observed that cancer and non-cancer areas in serrated lesions, particularly SSA/Ps, were categorized as mixed type (gastric plus intestinal types). This finding is consistent with a previous study by Gibson et al (34), who demonstrated that the levels of MUC1, MUC2, and MUC5AC expression were not different between SSA/Ps with and without cancer. Therefore, malignant transformation from SSA/Ps, but not from HPs or TSAs, may occur without changes in the mucin phenotype.

Although the present study yielded a number of important findings, its limitations were that it was a retrospective single-center study. Therefore, prospective studies in larger populations are required to validate the results of the present study. In addition to using endoscopic imaging techniques, it would also be useful if molecular or clinical markers were identified that can predict which serrated lesions are at an increased risk of progression to cancer.

In conclusion, the present retrospective analysis of the endoscopic features of serrated lesions with cancer was useful for delineating their characteristic endoscopic features and for aiding in treatment selection.

\section{Acknowledgements}

The abstract was presented at the meeting of the American Society for Gastrointestinal Endoscopy (May 21, 2016; San Diego, CA, USA) and was published as abstract no. Su1619 in Gastrointestinal Endoscopy 83 (Suppl): 2016.

\section{Funding}

The present study was supported in part by a Grant-in-Aid from the Japanese Ministry of Education, Culture and Science (grant no. 25460964).

\section{Availability of data and materials}

The datasets generated and analyzed in the present study are included in this published article.

\section{Authors' contributions}

SN, KM, OT, and TT contributed to the concept and design of the study. SN, HK, TN, YM, MM, HT, SY, KK, and OT contributed to management of the patient. SN, KM, JA, and OT contributed to analysis and interpretation of the data. SN and KM contributed to writing the manuscript. All authors contributed to the manuscript and read and approved the final manuscript.

\section{Ethics approval and consent to participate}

The Ethics Committee of Kurume University Hospital approved the study protocol. Written informed consent was gained from all participants.

\section{Consent for publication}

The study participants provided consent for the data to be published.

\section{Competing interests}

The authors declare that they have no competing interests.

\section{References}

1. Morson BC: Precancerous and early malignant lesions of the large intestine. Br J Surg 55: 725-731, 1968.

2. Muto T, Bussey HJ and Morson BC: The evolution of cancer of the colon and rectum. Cancer 36: 2251-2270, 1975 .

3. Torlakovic E, Skovlund E, Snover DC, Torlakovic G and Nesland JM: Morphologic reappraisal of serrated colorectal polyps. Am J Surg Pathol 27: 65-81, 2003.

4. Jass JR: Classification of colorectal cancer based on correlation of clinical, morphological and molecular features. Histopathology 50: 113-30, 2007.

5. Cunningham KS and Riddell RH: Serrated mucosal lesions of the colorectum. Curr Opin Gastroenterol 22: 48-53, 2006.

6. Snover D, Ahnen D, Burt R, et al: Serrated polyps of the colon and rectum and serrated polyposis. In: WHO Classification of Tumours of the Digestive System. 4th edition. Bosman F, Carneiro F, Hruban R and Theise N (eds). IARC Press, Lyon, pp160-165, 2000.

7. Kambara T, Simms LA, Whitehall VL, Spring KJ, Wynter CV, Walsh MD, Barker M, Arnold S, McGivern A, Matsubara N, et al: BRAF mutation is associated with DNA methylation in serrated polyps and cancers of the colorectum. Gut 53: 1137-1144, 2004.

8. Jass JR: Serrated adenoma of the colorectum and the DNA-methylator phenotype. Nat Clin Pract Oncol 2: 398-405, 2005.

9. O'Brien M: Hyperpalastic and serrated polyps of the colorectum. Gastroenterol Clin North Am 36: 947-968, 2007.

10. Axelrad AM, Fleischer DE, Geller AJ, Nguyen CC, Lewis JH, Al-Kawas FH, Avigan MI, Montgomery EA and Benjamin SB: High-resolution chromoendoscopy for the diagnosis of diminutive colon polyps: Implications for colon cancer screening. Gastroenterology 110: 1253-1258, 1996.

11. Fu KI, Sano Y, Kato S, Fujii T, Nagashima F, Yoshino T, Okuno T, Yoshida S and Fujimori T: Chromoendoscopy using indigo carmine dye spraying with magnifying observation is the most reliable method for differential diagnosis between non-neoplastic and neoplastic colorectal lesions: A prospective study. Endoscopy 36: 1089-1093, 2004.

12. Hasegawa S, Mitsuyama K, Kawano H, Arita K, Maeyama Y, Akagi Y, Watanabe Y, Okabe Y, Tsuruta O and Sata M: Endoscopic discrimination of sessile serrated adenomas from other serrated lesions. Oncol Lett 2: 785-789, 2011.

13. Tadepalli US, Feihel D, Miller KM, Itzkowitz SH, Freedman JS, Kornacki S, Cohen LB, Bamji ND, Bodian CA and Aisenberg J: A morphologic analysis of sessile serrated polyps observed during routine colonoscopy (with video). Gastrointest Endosc 74: 1360-1368, 2011.

14. Hazewinkel Y, López-Cerón M, East JE, Rastogi A, Pellisé M, Nakajima T, van Eeden S, Tytgat KM Fockens P and Dekker E: Endoscopic features of sessile serrated adenomas: Validation by international experts using high-resolution white-light endoscopy and narrow-band imaging. Gastrointest Endosc 77: 916-924, 2013.

15. Rosty C, Hewett DG, Brown IS, Leggett BA and Whitehall VL: Serrated polyps of the large intestine: Current understanding of diagnosis, pathogenesis, and clinical management. J Gastroenterol 48: 287-302, 2013. 
16. Buda A, De Bona M, Dotti I, Piselli P, Zabeo E, Barbazza R, Bellumat A, Valiante F, Nardon E, Probert CS, et al: Prevalence of different subtypes of serrated polyps and risk of synchronous advanced colorectal neoplasia in average-risk population undergoing first-time colonoscopy. Clin Transl Gastroenterol 3: e6, 2012.

17. Bouwens MW, van Herwaarden YJ, Winkens B, Rondagh EJ, de Ridder R, Riedl RG, Driessen A, Dekker E, Masclee AA and Sanduleanu S: Endoscopic characterization of sessile serrated adenomas/polyps with and without dysplasia. Endoscopy 46 : 225-235, 2014

18. Kudo S, Hirota S, Nakajima T, Hosobe S, Kusaka H, Kobayashi T, Himori M and Yagyuu A: Colorectal tumours and pit pattern. J Clin Pathol 47: 880-885, 1994.

19. Kudo S, Tamura S, Nakajima T, Yamano H, Kusaka $\mathrm{H}$ and Watanabe H: Diagnosis of colorectal tumorous lesions by magnifying endoscopy. Gastrointest Endosc 44: 8-14, 1996.

20. Tobaru T, Mitsuyama K, Tsuruta O, Kawano H and Sata M: Sub-classification of type VI pit patterns in colorectal tumors: Relation to the depth of tumor invasion. Int J Oncol 33: 503-508, 2008.

21. Sano Y, Ikematsu H, Fu KI, Emura F, Katagiri A, Horimatsu T, Kaneko K, Soetikno R and Yoshida S: Meshed capillary vessels by use of narrow-band imaging for differential diagnosis of small colorectal polyps. Gastrointest Endosc 69: 278-283, 2009.

22. Uraoka T, Saito Y, Ikematsu H, Yamamoto K and Sano Y: Sano's capillary pattern classification for narrow-band imaging of early colorectal lesions. Dig Endosc 1: 112-125, 2011.

23. Soetikno RM, Kaltenbach T, Rouse RV, Park W, Maheshwari A, Sato T, Matsui S and Friedland S: Prevalence of nonpolypoid (flat and depressed) colorectal neoplasms in asymptomatic and symptomatic adults. JAMA 299: 1027-1035, 2008.

24. Schlemper RJ, Riddell RH, Kato Y, Borchard F, Cooper HS Dawsey SM, Dixon MF, Fenoglio-Preiser CM, Fléjou JF, Geboes K, et al: The Vienna classification of gastrointestinal epithelial neoplasia. Gut 47: 251-255, 2000.

25. Shiroshita H, Watanabe H, Ajioka Y, Watanabe G, Nishikura K, and Kitano S.Re-evaluation of mucin phenotypes of gastric minute well-differentiated-type adenocarcinomas using a series of HGM, MUC5AC, MUC6, M-GGMC, MUC2 and CD10 stains. Pathol Int 54: 311-321, 2004
26. Fujita K, Hirahashi M, Yamamoto H, Matsumoto T, Gushima M, Oda Y, Kishimoto J, Yao T, Iida M and Tsuneyoshi M: Mucin core protein expression in serrated polyps of the large intestine. Virchows Arch 457: 443-449, 2010.

27. Shiroshita H, Watanabe H,Ajioka Y,Watanabe G, Nishikura Kand Kitano S: Re-evaluation of mucin phenotypes of gastric minute well-differentiated-type adenocarcinomas using a series of HGM, MUC5AC, MUC6, M-GGMC, MUC2 and CD10 stains. Pathol Int 54: 311-321, 2004.

28. Jass JR, Whitehall VL, Young J and Leggett BA: Emerging concepts in colorectal neoplasia. Gastroenterology 123: 862-876, 2002.

29. Leggett B and Whitehall V: Role of the serrated pathway in colorectal cancer pathogenesis. Gastroenterology 138: 2088-2100, 2010.

30. Oono Y, Fu K, Nakamura H, Iriguchi Y, Yamamura A, Tomino Y, Oda J, Mizutani M, Takayanagi S, Kishi D, et al: Progression of a sessile serrated adenoma to an early invasive cancer within 8 months. Dig Dis Sci 54: 906-909, 2009.

31. Horii J, Kato J, Nagasaka T, Hiraoka S, Sun DS, Watanabe K, Fujita I, Toyokawa T, Tomoda J and Yamamoto K: Development of invasive colon cancer with microsatellite instability in a patient with hyperplastic polyposis syndrome. Jpn J Clin Oncol 42: 451-454, 2012.

32. Torlakovic EE, Gomez JD, Driman DK, Parfitt JR, Wang C, Benerjee T and Snover DC: Sessile serrated adenoma (SSA) vs. traditional serrated adenoma (TSA). Am J Surg Pathol 32: 21-29, 2008.

33. Oue N, Sentani K, Sakamoto N and Yasui W: Clinicopathologic and molecular characteristics of gastric cancer showing gastric and intestinal mucin phenotype. Cancer Sci 106: 951-918, 2015.

34. Gibson JA, Hahn HP, Shahsafaei A and Odze RD: MUC expression in hyperplastic and serrated colonic polyps: Lack of specificity of MUC6. Am J Surg Pathol 35: 742-749, 2011. 